\title{
Contribution of understorey vegetation to evapotranspiration partitioning in apple orchards under Mediterranean climatic conditions in South Africa
}

\author{
Z. Ntshidi ${ }^{\text {a,b,* }}$, S. Dzikiti ${ }^{\text {a,b,c }}$, D. Mazvimavi ${ }^{\text {b }}$, N.T. Mobe ${ }^{a, b}$ \\ ${ }^{a}$ Council for Scientific and Industrial Research (CSIR), Smart Places Cluster, Stellenbosch, South Africa \\ ${ }^{\mathrm{b}}$ Institute for Water Studies, Department of Earth Sciences, University of the Western Cape, Bellville, South Africa \\ ${ }^{\mathrm{c}}$ Department of Horticultural Science, Stellenbosch University, Stellenbosch, South Africa
}

\section{A R T I C L E I N F O}

Handling Editor - J.E. Fernández

\section{Keywords:}

Canopy cover

Irrigation

Sap flow

Soil evaporation

Transpiration model

\begin{abstract}
A B S T R A C T
Orchard evapotranspiration (ET) is a complex flux which has been the subject of many studies. It often includes transpiration from the trees, cover crops and weeds, evaporation from the soil, mulches and other orchard artefacts. In this study we investigated the contribution of the orchard floor evaporative fluxes to whole orchard ET focusing on the transpiration dynamics of understorey vegetation which is currently not well known. Data on the partitioning of ET into its constituent components were collected in apple (Malus Domestica Bork) orchards with varying fractional canopy cover. The study orchards were in the prime apple growing regions in South Africa. The orchards were planted to the Golden Delicious/Reinders and the red cultivars (i.e. Cripps' Pink/ Royal Gala/ Fuji). Tree transpiration was quantified using the heat ratio method and the thermal dissipation sap flow techniques. Understorey transpiration was measured at selected intervals using micro stem heat balance sap flow gauges calibrated against infrared gas analyser readings. Orchard ET was measured using an open path eddy covariance system while the microclimate, radiation interception, and soil evaporation were also monitored. Orchard floor evaporative fluxes accounted for as much as $80 \%$ of the measured ET in young orchards with dense understorey vegetation that covered most of the orchard floor. In these orchards the understorey transpiration was of the same order of magnitude as the bare moist soil evaporation suggesting that water use by the understorey vegetation was substantial. However, in mature orchards with a high canopy cover $(>55 \%$ fractional cover), orchard floor water losses were less than $30 \%$ of the measured ET. Understorey transpiration rates were much lower, contributing less than $10 \%$ of the whole orchard ET. Significant volumes of water can be saved, especially in young orchards, by keeping the orchard floor vegetation short, reducing the area occupied by understorey vegetation, and by reducing the wetted ground surface area.
\end{abstract}

\section{Introduction}

In South Africa, as elsewhere in the semi-arid climates, the availability of adequate water for irrigation is the biggest risk to sustainable fruit production. South Africa is a major exporter of fresh apples (Malus domestica Borkh.), being second only to Chile in the Southern hemisphere (Pienaar and Boonzaaier, 2018). The major apple growing region in South Africa is the Western Cape Province which has a Mediterranean-type climate and the rain falls outside the fruit growing season in winter (May to August). Consequently, all the fruit are grown under irrigation yet water resources in the country are under great strain. The Western Cape region, for example, is projected to experience severe water shortages in future due to rising competition between irrigated agriculture, increasing industrial activities, and the rapidly growing population of the Cape Town Metropolitan (Dzikiti et al., 2018a; Gush et al., 2019). Climate change is also projected to exacerbate the water problems by increasing the frequency and severity of droughts and extreme weather events in the region (Midgley and Lotze, 2011).

Sustainable management of irrigation requires accurate quantitative information on evapotranspiration (ET) which is the second largest water balance component in orchards (Villalobos et al., 2013). Many studies have quantified ET in apple orchards (Gush et al., 2019; Gush and Taylor, 2014; Li et al., 2007; Mobe et al., 2020; Ntshidi et al., 2018; Volschenk, 2017; Zanotelli et al., 2019). Besides the work by Li et al. (2007) and Wang and Wang (2017), few studies have investigated, in detail, the partitioning of evapotranspiration into its constituent

\footnotetext{
* Correspondence to: Council for Scientific and Industrial Research (CSIR), Smart Places Cluster, 11 Jan Cilliers Street, Stellenbosch, 7599, South Africa.

E-mail addresses: zntshidi@csir.co.za (Z. Ntshidi), sdzikiti@sun.ac.za (S. Dzikiti), Dmazvimavi@uwc.ac.za (D. Mazvimavi), Tmobe@csir.co.za (N.T. Mobe).
} 
components in apple orchards of varying age groups. To our knowledge there is a paucity of detailed information on the transpiration dynamics of understorey vegetation which is often present especially in orchards with non-localized irrigation systems e.g. micro-sprinkler, flood, etc. Little is also known about how the understorey transpiration is affected by canopy cover of apple trees from planting until the trees reach full-bearing age or maturity. This study therefore seeks to close this important information gap in order to gain insights on the role that understorey vegetation plays in the water balance of apple orchards.

Understanding the partitioning of ET in orchards is very important, especially in dry countries to quantify the proportion of beneficial water used to produce fruit (Kool et al., 2014; Wang and Wang, 2017). It also gives irrigation managers opportunities to identify and implement practices to reduce orchard floor evaporative fluxes to improve water productivity (Dzikiti et al., 2017; Dzikiti et al., 2018b; Fernández et al., 2018; Ortega-Farias, 2012). In addition, ET partitioning data is also important for evaluating multiple source water use models in agricultural and hydrological studies and in climate modelling (Anderson et al., 2017,2018 ,). Few studies have directly measured all the components of ET in crop fields. For example, in a comprehensive review of 52 publications of ET partitioning, Kool et al. (2014) found that 32 of the studies showed that soil evaporation $\left(E_{s}\right)$ contributed more than $30 \%$ of ET. Only 20 of the studies independently quantified both $\mathrm{E}_{\mathrm{s}}$ and $\mathrm{T}$ as well as ET. In this study we, for the first time, extend these measurements by collecting detailed data not only of $\mathrm{E}_{\mathrm{s}}$ and $\mathrm{T}$, but also of understorey transpiration $\left(\mathrm{T}_{\mathrm{c}}\right)$ which has not been quantified in apple orchards.

In most orchards, the understorey vegetation is either single species of exotic cover crops planted between the tree rows or indigenous vegetation, weeds or complex mixtures of these. Grasses are the most common cover crops planted in South African apple orchards for a variety of reasons. Examples include the tall fescue (Festuca arundinacea), kikuyu grass (Pennisetum clandestinum) and rye grass (Lolium), among others. They are used in orchards; i) to reduce soil erosion, ii) for improving the soil health (as living mulches and for nitrogen fixation), iii) for phytosanitary purposes by attracting and feeding beneficiary insects, and; iv) for aesthetic benefits, among others (Jannoyer et al., 2011). However, there is a strong, and yet unconfirmed, suspicion that the cover crops also contribute to an increased orchard water use.

The overall aim of this study is therefore to examine, in detail, the partitioning of evapotranspiration in apple orchards with a special focus on the role of the understorey vegetation. We also investigate how the ET partitioning varies with tree canopy cover which is a function of both the tree age and cultivar. For instance, the red apple cultivars are maintained with more open canopies, and hence, low vegetation cover, to encourage the development of the red colour on the fruit (Wiehann Steyn, pers. comm.). Apple cultivars that are susceptible to sunburn damage e.g. Golden Delicious, Granny Smith etc. are usually allowed to develop dense canopy cover (Mupambi et al., 2018) to provide shade for the fruit. Lastly, to better understand how the contribution of the understorey transpiration to orchard ET varies with management and with canopy cover of the apple trees during the course of the growing season, we developed a simple model to estimate understorey vegetation transpiration. We used the model to gain insights on the implications of various understorey management practices on orchard ET partitioning through model sensitivity analyses.

\section{Materials and methods}

\subsection{Description of study sites}

Data were collected over two growing seasons (October to May) i.e. $2016 / 17$, and $2017 / 18$ in five orchards in the prime apple growing regions in the Western Cape Province of South Africa. Detailed descriptions of the study areas are given in Dzikiti et al. (2018a, 2018b) and in Mobe et al. (2020). Two orchards were in the Koue Bokkeveld (KBV) region located about $180 \mathrm{~km}$ to the north of the City of Cape Town. The KBV region experiences hot summer temperatures and very cold winters with occasional snow fall over high lying areas. The third orchard was located close to the town of Vyeboom about $90 \mathrm{~km}$ to the east of Cape Town, while the other two orchards were close to the town of Grabouw, about $70 \mathrm{~km}$ to the south east of Cape Town. Climate in the Vyeboom and Grabouw areas is mild compared to KBV due to the moderating effect of the nearby Atlantic Ocean.

The selected orchards had contrasting characteristics in terms of tree canopy cover, cultivar, understorey vegetation, and management practices. One orchard in KBV was planted to the five year old Golden Delicious/Reinders apple trees on the M793 rootstock (hereafter called Orchard 1). The Golden Delicious cultivar is the most widely planted cultivar in South Africa accounting for close to $30 \%$ of the area under apples (Hortgro, 2018). In this orchard, the understorey vegetation was patchy comprising of a mixture of the tall fescue cover crop and weeds covering a strip about $1.1 \mathrm{~m}$ wide in the middle of the tree row. Tree spacing was about $4.0 \times 1.5 \mathrm{~m}$, giving 1667 trees per hectare. The second orchard (Orchard 2) in KBV was planted to seven year old Cripps' Pink apple trees on M793 rootstock. This cultivar is a high value and late maturing cultivar under South African conditions. The area under Cripps' Pink apples is rapidly growing in South Africa due to the high economic returns and reduced sunburn damage (Mupambi et al., 2018). The understorey vegetation in this orchard was a dense mixture of weeds and indigenous grasses mainly the buffalo grass (Penicum maximum) and gum grass (Eragrostis gummiflua) (see Fig. 1a). Tree spacing was about $4.5 \times 2.0 \mathrm{~m}$ giving 1111 trees per hectare. The understorey vegetation was in the middle of the tree rows, but extending over a larger surface area with an average width of about $1.7 \mathrm{~m}$. Apple trees in South Africa typically reach full-bearing age between seven and eight years after planting. Therefore all orchards between four and seven years old are referred to as "medium bearing" orchards in this study. Soil types for the two KBV sites were deep sandy to sandy loam soils of the Fernwood soil form (Hyperalbic Arenosol) according to the Soil Classification Working Group, S.C.W. (1991).

The third orchard (Orchard 3), located in Vyeboom, was also a five year old medium bearing orchard planted to the Golden Delicious/ Reinders cultivar on the M7 rootstock. Tree spacing was $4.0 \times 2.0 \mathrm{~m}$ giving a density of 1250 plants per hectare. The understorey vegetation was a dense tall fescue cover crop which grew between the tree rows. However, the cover crop was restricted to a thin strip which was only about $0.75 \mathrm{~m}$ wide on average and it was kept lash green by irrigation (see Fig. 1b). The fourth orchard (Orchard 4) was a mature 26 year old Golden Delicious apple block in Grabouw on M793 rootstock. Tree spacing was about $4.25 \times 2.00 \mathrm{~m}$ and the maximum fractional vegetation cover at the midseason stage was about 0.64 . The intense shading by the large canopies restricted the understorey vegetation to a thin strip, about $0.50 \mathrm{~cm}$ wide on average comprising of the tall fescue species. The last orchard (Orchard 5) was a young non-bearing Fuji orchard which was two years old and located next to the mature Golden Delicious orchard. Tree spacing was about $3.5 \times 2.0 \mathrm{~m}$ and there was a dense understorey vegetation in the middle of the row with an average width of about $1.9 \mathrm{~m}$ (see Fig. 1c). Fractional vegetation cover of the young trees at the midseason stage was less than 0.20 . The soils in the three Vyeboom and Grabouw orchards were the dark red clayey loam soils of the Kroonstad soil form according to the Soil Classification Working Group, S.C.W. (1991). All the five orchards in this study were irrigated by a micro-sprinkler system with one sprinkler per tree delivering about 30 litres of water per hour. The wetted area extended between 1.0 and $1.2 \mathrm{~m}$ away from the micro-sprinkler. Data collection in Orchards 1-3 was done during the $2016 / 17$ growing season while that in Orchards 4 and 5 was collected during the 2017/18 season and Table 1 summarizes all the orchard attributes. 

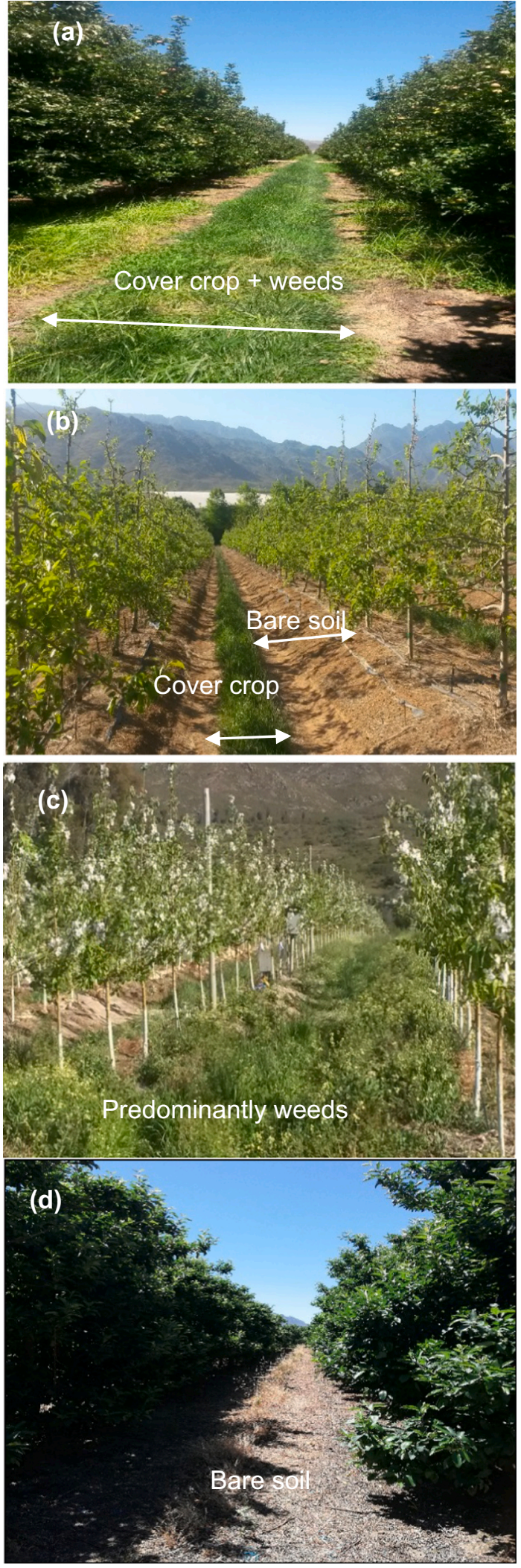

Fig. 1. Various orchard floor management practices showing; (a) a wide understorey strip with a mixture of planted cover crop and weeds; b) a thin single species strip of tall fescue cover crop, (c) a poorly managed orchard floor with a dense cover of weeds and cover crops; and (d) a bare orchard floor typical of drip irrigated orchards.

\subsection{Data collection}

\subsubsection{Site microclimate measurements}

Weather data were measured using automatic weather stations located next to the orchards for Orchards 1 and 2. Data for orchards 3, 4 and 5 were collected from the network operated by the Agricultural Research Council (ARC) located less than $3.0 \mathrm{~km}$ away. The stations were installed over uniform short grass surface whose attributes resemble the grass reference crop (Allen et al., 1998). Equipment used for Orchards 1 and 2 weather data comprised pyranometers (Model: SP 212 Apogee Instruments, Inc., Logan UT, USA), which measured the solar irradiance, air temperature and relative humidity probes (Model: HMP60 Campbell Scientific, Inc., Logan UT, USA) installed about $2.0 \mathrm{~m}$ above the ground. A three cup anemometer and wind vane (Model R. M. Young Wind Sentry Set model 03001, Campbell Scientific, Inc., Logan UT, USA) were used to measure wind speed and direction, respectively at $2.0 \mathrm{~m}$ height, while rainfall was recorded using a tipping bucket rain gauge (Model: TE525-L; Campbell Scientific, Inc., Logan UT, USA). All the sensors were connected to data loggers (Model: CR1000 Campbell Scientific, Inc., Logan UT, USA) programmed with a scan interval of $10 \mathrm{~s}$. The output signals were processed at hourly and daily intervals.

\subsubsection{Sap flow dynamics, leaf area index, and orchard evapotranspiration}

In South Africa, the apple growing season is eight to ten months long (September/October to May/June) depending on cultivar. In this study tree transpiration was measured for the entire growing season in each of the five orchards using the heat ratio method (HRM) (Burgess et al., 2001) sap flow sensors installed on between three and six trees in the mature and medium bearing orchards. The HRM systems comprised heaters implanted into the stems and connected to custom-made relay control modules which controlled the heat application. T-type thermocouple pairs, installed at equal distances $(\sim 0.5 \mathrm{~cm})$ up and downstream of each heater probe measured the sapwood temperature. The thermocouples were then connected to multiplexers (Model: AM16/32B Campbell Scientific, Logan UT, USA) which were in turn connected to CR1000 data loggers as described in Dzikiti et al. (2018a). Four sets of sensors were installed in the four cardinal directions around the stem on each of the six trees to account for the azimuthal variations in sap velocity (López-Bernal et al., 2010). The sensors were inserted at different depths into the sapwood to capture the radial variation in sap velocity as described by Wullschleger and King (2000). The HRM data were corrected for wounding due to sensor implantation at the end of the experiment according to the procedure by Swanson and Whitfield (1981). The conducting sapwood area was determined by injecting a weak solution of methylene blue dye into the stems to determine the extent of the active xylem vessels. Whole-tree transpiration was derived as the sum of the sap flows in four concentric rings in the sapwood with flow in each ring calculated as the product of the sap velocity at each probe depth and the sapwood area represented by that probe. In this study, we did not calibrate the HRM sap flow method so our results represent un-calibrated values. In the young non-bearing orchard with smaller stems, Granier probes (Model TDP 10, Dynamax, Houston, USA) were used. The sensors were installed on trees with different stem sizes to account for the tree to tree variation in the water use rates. The Granier probes were calibrated on young apple trees using weighing lysimeters as described by Dzikiti et al. (2018b).

The orchard leaf area index (LAI) for the trees was measured at roughly monthly intervals throughout the growing season using an LAI2000 Plant Canopy Analyser (LI-COR Inc., Lincoln, NE, USA). The data were collected when there was no direct solar radiation either before sunrise or after sunset when the tree leaves behaved like black bodies.

Evapotranspiration (ET) from the orchards was measured using an open path eddy covariance system with sensors mounted on a $10 \mathrm{~m}$ lattice mast. The system was deployed in the orchards during short window periods lasting a few days due to equipment limitations. The sensors comprised a 3D sonic anemometer (Model: CSAT3, Campbell 
Table 1

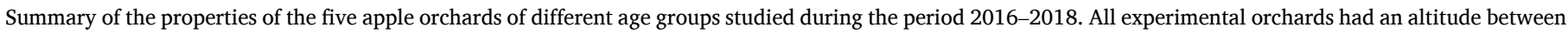
300 and $400 \mathrm{~m}$ above sea level. $\mathrm{LAI}_{\mathrm{c}}$ is the recorded peak leaf area index over the understorey strip.

\begin{tabular}{|c|c|c|c|c|c|c|c|c|c|c|c|c|}
\hline \multicolumn{13}{|c|}{ 2016/17 SEASON } \\
\hline Region & $\begin{array}{l}\text { Orchard } \\
\text { number }\end{array}$ & Cultivar & Age group & $\begin{array}{l}\text { Tree } \\
\text { density }\end{array}$ & $\begin{array}{l}\text { Orchard } \\
\text { size (ha) }\end{array}$ & Rootstock & $\begin{array}{l}\text { Age } \\
\text { (years) }\end{array}$ & $\begin{array}{l}\text { Tree } \\
\text { height }\end{array}$ & LAI & $\mathrm{LAI}_{\mathrm{c}}$ & $\begin{array}{l}\text { Fractional } \\
\text { understorey } \\
\text { cover }\end{array}$ & Coordinates \\
\hline KBV & 1 & $\begin{array}{l}\text { Golden } \\
\text { Delicious }\end{array}$ & $\begin{array}{l}\text { Medium- } \\
\text { bearing }\end{array}$ & 1667 & 3 & M793 & 5 & 3.5 & 1.5 & 0.15 & 0.28 & $\begin{array}{l}\mathrm{S} 32^{\circ} 57^{\prime} 01^{\prime \prime} \\
\mathrm{E} 019^{\circ} 12^{\prime} 26^{\prime \prime}\end{array}$ \\
\hline KBV & 2 & $\begin{array}{l}\text { Cripps' } \\
\text { Pink }\end{array}$ & $\begin{array}{l}\text { Medium- } \\
\text { bearing }\end{array}$ & 1111 & 3.5 & M793 & 7 & 3.5 & 2 & 0.16 & 0.38 & $\begin{array}{l}\mathrm{S}^{\prime} 3^{\circ} 21^{\prime} 55^{\prime \prime} \\
\mathrm{E} 019^{\circ} 19^{\prime} 20^{\prime \prime}\end{array}$ \\
\hline Vyeboom & 3 & $\begin{array}{l}\text { Golden } \\
\text { Reinders }\end{array}$ & $\begin{array}{l}\text { Medium- } \\
\text { bearing }\end{array}$ & 1250 & 6 & M7 & 5 & 3.5 & 1.3 & 0.14 & 0.19 & $\begin{array}{l}\mathrm{S} 34^{\circ} 4^{\prime} 5^{\prime \prime} \\
\mathrm{E} 019^{\circ} 6^{\prime} 42^{\prime \prime}\end{array}$ \\
\hline \multicolumn{13}{|c|}{$2017 / 18$ SEASON } \\
\hline Grabouw & 4 & $\begin{array}{l}\text { Golden } \\
\text { Delicious }\end{array}$ & $\begin{array}{l}\text { Full- } \\
\text { bearing }\end{array}$ & 1176 & 5.1 & M793 & 26 & 4 & 3.5 & 0.17 & 0.12 & $\begin{array}{l}\mathrm{S} 34^{\circ} 954^{\prime} 18^{\prime \prime} \\
\mathrm{E} 019^{\circ} 437^{\prime} 2^{\prime \prime}\end{array}$ \\
\hline Grabouw & 5 & Fuji & $\begin{array}{l}\text { Non- } \\
\text { bearing }\end{array}$ & 1667 & 2.8 & M109 & 2 & 3 & 1 & 0.35 & 0.54 & $\begin{array}{l}\text { S34 } 95^{\prime} 27.6^{\prime \prime} ; \\
\text { E019 } 43^{\prime} 40.8^{\prime \prime}\end{array}$ \\
\hline
\end{tabular}

Sci. Inc., Utah, USA) that measured the wind speed in the $\mathrm{x}-\mathrm{y}$ and $\mathrm{z}$ directions. An infrared gas analyser (IRGA) (Model: LI-7500A, LI-COR Inc., Nebraska, USA) was used to quantify the concentration of atmospheric water vapour and carbon dioxide. The sensors were connected to a CR5000 data logger manufactured by Campbell Scientific. Additional sensors to quantify the orchard energy balance included a single component net radiometer (Model CNR1: Kipp \& Zonen, The Netherlands) which was installed at about $8.0 \mathrm{~m}$ height from the ground. Two clusters of soil heat flux plates (Hukseflux, The Netherlands) were installed at $8 \mathrm{~cm}$ depth below the surface to measure the soil heat fluxes under the canopies and between the tree rows. Soil averaging thermocouples (Model: TCAV, Campbell Sci. Inc., Utah, USA) were installed above each set of soil heat flux plates at 2 and $6 \mathrm{~cm}$ depths from the surface to correct the measured fluxes for the energy stored by the soil above the plates. The high frequency data, collected at $10 \mathrm{~Hz}$, was stored on a 2 GB memory card. The height of the trees ranged from 3.0 to $4.5 \mathrm{~m}$ (see Table 1 ) while the orchard sizes varied from just under 3.0 ha up to about 6.5 ha. In all the orchards the flux tower was located downwind of the prevailing wind direction to maximize the fetch upwind of the tower. The IRGA and sonic sensors were mounted between 1.3 and $1.6 \mathrm{~m}$ above the average canopy height depending on orchard size and data emanating from outside the study area were excluded. The high frequency data were post-processed to correct for air density fluctuations, lack of sensor levelness (coordinate rotation), sensor separation, sensor response times etc. using the EddyPro v 6.2.0 software (LICOR Inc., Nebraska, USA). The data were further corrected for lack of energy balance closure using the Bowen ratio method as described by Cammalleri et al. (2010).

\subsubsection{Understorey vegetation, radiation interception, and soil evaporation}

The understorey vegetation management practices varied widely between orchards. To monitor changes in the orchard floor characteristics, we requested the participating farms to record dates when they performed operations such as mowing of the understorey vegetation or application of herbicides throughout the growing season. For example, in the mature orchard (Orchard 4) and medium bearing orchards (Orchard 1 and 3), the understorey vegetation was mowed roughly on a monthly basis using a cutter mounted on a tractor. The medium bearing 'Cripps' Pink' orchard (Orchard 2) was mowed at irregular intervals during the growing season while the young non-bearing 'Fuji' orchard (Orchard 5) was only mowed at the beginning and end of the season.

The leaf area index of the understorey vegetation $\left(\mathrm{LAI}_{\mathrm{c}}\right)$ was measured at roughly monthly intervals in Orchards 3, 4 and 5. This was done using a destructive approach wherein a $50 \mathrm{~cm} \times 50 \mathrm{~cm}$ sampling grid was used to mark four to five random positions occupied by the vegetation within the understorey strip. All the vegetation enclosed in the grid was cut to ground level and their leaf area measured manually in the lab using the leaf area meter (Model Li-3000, Li-COR Inc., Nebraska, USA). The leaf area index of the understorey strips were then estimated as the ratio of the understorey leaf area to the grid area (2 $500 \mathrm{~cm}^{2}$ ), and an average value was calculated. To establish the drivers of water use by the understorey vegetation, we measured the photosynthetically active radiation (PAR) that was intercepted by the understorey plants at selected intervals. These data were measured using a ceptometer (Model: LP-80 AccuPar; Decagon, USA) at six marked positions with different sun-shade exposures on the orchard floor. The fraction of the PAR intercepted by the understorey vegetation was then calculated as the ratio of the average PAR under the canopies to that incident at the top of the tree canopies. The specific dates when these data were collected in each orchard are shown in Table 2.

Evaporation from the bare soil was monitored, also for selected days, using micro-lysimeters according to the data collection schedule in Table 2. The selected periods coincided with days when the eddy covariance flux tower was operational in the respective orchards. Eight PVC micro-lysimeters were installed at different sun-shade and wet-dry locations on the orchard floor. The changes in the mass of the microlysimeters were monitored at hourly intervals using a precision mass balance with a resolution of $0.01 \mathrm{~g}$ from sunrise to sun set according to the schedule in Table 2. The soil used in the micro-lysimeters was replaced after every $12 \mathrm{~h}$ for consecutive measurement days. The whole

Table 2

Dates for the various campaigns to measure water use partitioning in five orchards of different age groups and cultivars.

\begin{tabular}{|c|c|c|c|c|c|}
\hline Region & Orchard number & Cultivar & Age group & Measured variables & Measurement date \\
\hline KBV & 1 & GD & MB & ET, T, Es, Tc \& R(i) & 13-18 Nov 2016 \\
\hline KBV & 2 & $\mathrm{CP}$ & MB & $\mathrm{ET}, \mathrm{T}, \mathrm{E}_{\mathrm{s}}, \mathrm{T}_{\mathrm{c}} \& \mathrm{R}(\mathrm{i})$ & 12-13 Jul 2017 \\
\hline Vyeboom & 3 & GD & MB & $\mathrm{ET}, \mathrm{T}, \mathrm{E}_{\mathrm{s}}, \mathrm{Tc} \& \mathrm{R}(\mathrm{i})$ & 21-24 Feb 2017 \\
\hline Grabouw & 4 & GD & FB & $\mathrm{ET}, \mathrm{T}, \mathrm{E}_{\mathrm{s}}, \mathrm{T}_{\mathrm{c}} \& \mathrm{R}(\mathrm{i})$ & 12-15 Dec 2017 \\
\hline Grabouw & 5 & FJ & NB & $\mathrm{ET}, \mathrm{T}, \mathrm{E}_{\mathrm{s}}, \mathrm{T}_{\mathrm{c}} \& \mathrm{R}(\mathrm{i})$ & 8-10 Nov. 2017 \\
\hline
\end{tabular}

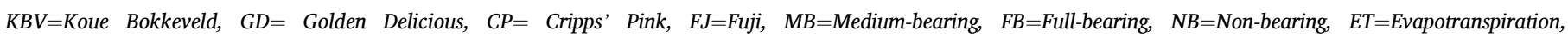
$T=$ Transpiration, $E_{s}=$ Soil evaporation, $T_{c}=$ Understorey transpiration, $R(i)=$ Radiation interception . 
surface soil evaporation was calculated as the weighted sum of the micro-lysimeter measurements with the area represented by each microlysimeter on the orchard floor used as the weights according to the approach by Testi et al., 2004.

\subsubsection{Measurement and modelling of understorey transpiration}

Given the wide range of understorey vegetation which grow in orchards (Fig. 1), we did not distinguish between the different species in this study. Instead we targeted the most common grass species for monitoring. Understorey transpiration was measured using miniature stem heat balance sap flow gauges (Model SGA3, Dynamax Inc., Houston, USA) and details of these micro sap flow sensors are given by Van Bavel and Van Bavel (1990). The understorey transpiration was also measured during periods when the eddy covariance flux tower was deployed in each orchard. The sap flow data were measured on between three and four understorey plants at hourly intervals for a few days. Careful precautions were taken to ensure that the sensors performed optimally according to the manufacturers' recommendations e.g. by carefully wrapping each gauge using several layers of reflective aluminium foil to ensure steady state conditions, cleaning the installation sites on the stems etc. However, given the proximity of the sensors to the ground, we suspected that strong thermal gradients could affect the quality of the data. So, we calibrated the micro sap flow sensor data against manual transpiration measurements taken using the portable Infrared Gas Analyser (Model: LI-6860, Portable Photosynthesis System, LI-COR Inc., Nebraska, USA). The IRGA data were collected in continuous cycles from sunrise to sunset over a period of two days. The micro sap flow sensor data were normalized with the transpiring leaf area for each instrumented plant. These data were directly compared with that from the IRGA to confirm the accuracy of the sap flow measurements.

To convert the sap flow gauge readings to transpiration expressed over the entire orchard floor $\left(\mathrm{T}_{\mathrm{c}}\right.$, in $\left.\mathrm{mm} / \mathrm{h}\right)$ first we normalised the sap flow (SF, in $\mathrm{cm}^{3} / \mathrm{h}$ ) of each instrumented plant with the leaf area (A, in $\mathrm{cm}^{2}$ ). Then we multiplied the average of the normalized sap flow with the understorey leaf area index $\left(\mathrm{LAI}_{\mathrm{c}}\right)$ and the fraction of the orchard floor occupied by the understorey vegetation $\left(f_{g}\right)$.

$T_{c}=\frac{\overline{S F}}{A} \times L A I_{c} \times f_{g} \times 10$

Since it was not practical to measure $T_{c}$ throughout the season, a simple model was developed to estimate the understorey transpiration. The model uses a modified version of the Priestley and Taylor approach in which we treat the understorey vegetation as a separate layer within the orchard. According to this approach

$T_{c}=\propto_{c}\left(1-\tau_{c}\right) E_{e q}$

where $\alpha_{c}$ is the Priestley and Taylor coefficient applied to the understorey canopy, $\tau_{c}$ is the understorey canopy transmission factor, and $E_{e q}$ is the equilibrium evaporation term (Slatyer and McIlroy, 1961), such that:

$\tau_{c}=e^{-k L A I c}$

where $\mathrm{k}$ is the extinction coefficient and we used a value of $0.7 . \mathrm{LAI}_{\mathrm{c}}$ is the understorey leaf area index. The equilibrium evaporation was calculated as:

$E_{e q}=\frac{\Delta}{\Delta+2 x 0.93 \gamma} R_{n g}$

where $R_{n g}\left(M J / \mathrm{m}^{2} / d\right)$ is the net radiation on the orchard floor (i.e. at the top of the understorey canopies), $\Delta(\mathrm{kPa} / \mathrm{K})$ is the slope of the saturation vapour pressure vs air temperature curve, and $\gamma(\mathrm{kPa} / \mathrm{K})$ is the psychrometric constant. Given the non-uniform vegetation cover in the orchards, the net radiation at the orchard floor was calculated using a dual source model proposed for olive orchards by Ortega-Farías et al.
(2016) in which:

$R_{n}=f_{r} R_{n c}+\left(1-f_{r}\right) R_{n s}$

where $R_{n}$ (in $M J / m^{2} / d$ ) is the net radiation at the orchard surface, $R_{n c}$ and $R_{n s}$ represent the net radiation at the tree canopy and soil surface, respectively (in $\mathrm{MJ} / \mathrm{m}^{2} / \mathrm{d}$ ) and $\mathrm{f}_{\mathrm{r}}$ is the fractional canopy cover at nadir. In this study $\left(1-\mathrm{f}_{\mathrm{r}}\right) \mathrm{R}_{\mathrm{ns}}$ is considered to be numerically equal to $\mathrm{R}_{\mathrm{ng}}$ in $\mathrm{Eq}$. 4. According to Ortega-Farías et al. (2016), $R_{n s}$ can be derived from:

$R_{n s}=\left(1-\alpha_{s}\right) R_{s}+L_{d}-L_{u p}-\left(1-\varepsilon_{s}\right) L_{d}$

where $R_{s}$ is the solar radiation $\left(M J / \mathrm{m}^{2} / \mathrm{d}\right)$ measured at the weather station, $L_{d}$ is the downwelling longwave radiation incident on the orchard floor, $\mathrm{L}_{\mathrm{up}}$ is the longwave radiation emitted by the orchard floor $\left(\mathrm{MJ} / \mathrm{m}^{2} / \mathrm{d}\right), \alpha_{\mathrm{s}}$ and $\varepsilon_{\mathrm{s}}$ represent the albedo and emissivity of the surface, respectively. We assumed that the surface albedo of the understorey vegetation was similar to that of a short grass reference crop at 0.23 , and we used the surface emissivity of 0.95 used by Ortega-Farías et al. (2016). According to Brutsaert (1975), $\mathrm{L}_{\mathrm{d}}$ can be calculated as:

$L_{d}=\varepsilon_{a} \sigma T_{a}^{4}$

where $T_{a}$ is the daily average air temperature in Kelvin, $\sigma$ is the StefanBoltzmann constant $\left(4.903 \times 10^{-9} \mathrm{MJ} \mathrm{K}^{-4} \mathrm{~m}^{-2} \mathrm{~d}^{-1}\right)$ and $\varepsilon_{\mathrm{a}}$ is the emissivity of the air calculated according to Brutsaert (1975) as:

$\varepsilon_{a=1.24}\left(\frac{e_{a}}{T_{a}}\right)^{\frac{1}{7}}$

where $e_{a}$ is the actual vapour pressure of the air (in $\mathrm{hPa}$ ). The emitted longwave radiation was calculated as:

$L_{u p}=\varepsilon_{s} \sigma T_{s}^{4}$

where $T_{s}$ is the surface temperature in Kelvin which we assumed to be equal to $\mathrm{T}_{\mathrm{a}}$.

According to Agam et al. (2010) the Priestley and Taylor coefficient ( $\alpha=1.26$ ) is variable and it is related to that at the vegetation canopy level $\left(\alpha_{c}\right)$ by:

$\aleph_{c}=\frac{\propto-\alpha_{s o} \tau_{c}}{1-\tau_{c}}$

where $\alpha_{\text {so }}$ is the Priestley and Taylor coefficient applied to the soil layer. For wet soil conditions, Agam et al. (2010) suggested that $\alpha_{\text {so }} \approx 1.0$. This is a reasonable assumption to make in this study given that a large portion of the orchard floor was wetted by the micro-sprinklers. So, combining Eqs. 2, 3, and 10, and assuming that $\alpha_{\mathrm{so}}=1$, then understorey transpiration can be calculated as a function of $\mathrm{LAI}_{\mathrm{c}}$, LAI and the orchard floor microclimate as:

$T_{c}=\left(1.26-e^{-k L A I c}\right) E_{e q}$

\section{RESULTS}

\subsection{Microclimate}

A summary of the climatic conditions during the 2016/17 and the 2017/18 growing season is shown in Table 3. The period 2016-2018 coincided with one of the worst droughts in living memory in the Western Cape Province which spanned over three consecutive years. However, despite concerns over water availability, the study orchards were prioritized and irrigated as in normal years. So the drought conditions did not skew the results of this study, particularly given that little rain falls during the growing season.

During the 2016/17 growing season, the Koue Bokkeveld (KBV) sites (Orchards 1 and 2) received only $37.9 \mathrm{~mm}$ of rainfall while Orchard 3 in Vyeboom received slightly higher rainfall at $55.0 \mathrm{~mm}$ from October 
Table 3

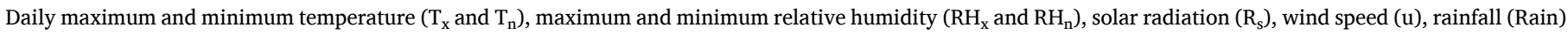
and reference evapotranspiration $\left(\mathrm{ET}_{\mathrm{o}}\right.$ ) at the Koue Bokkeveld, Vyeboom and Grabouw sites.

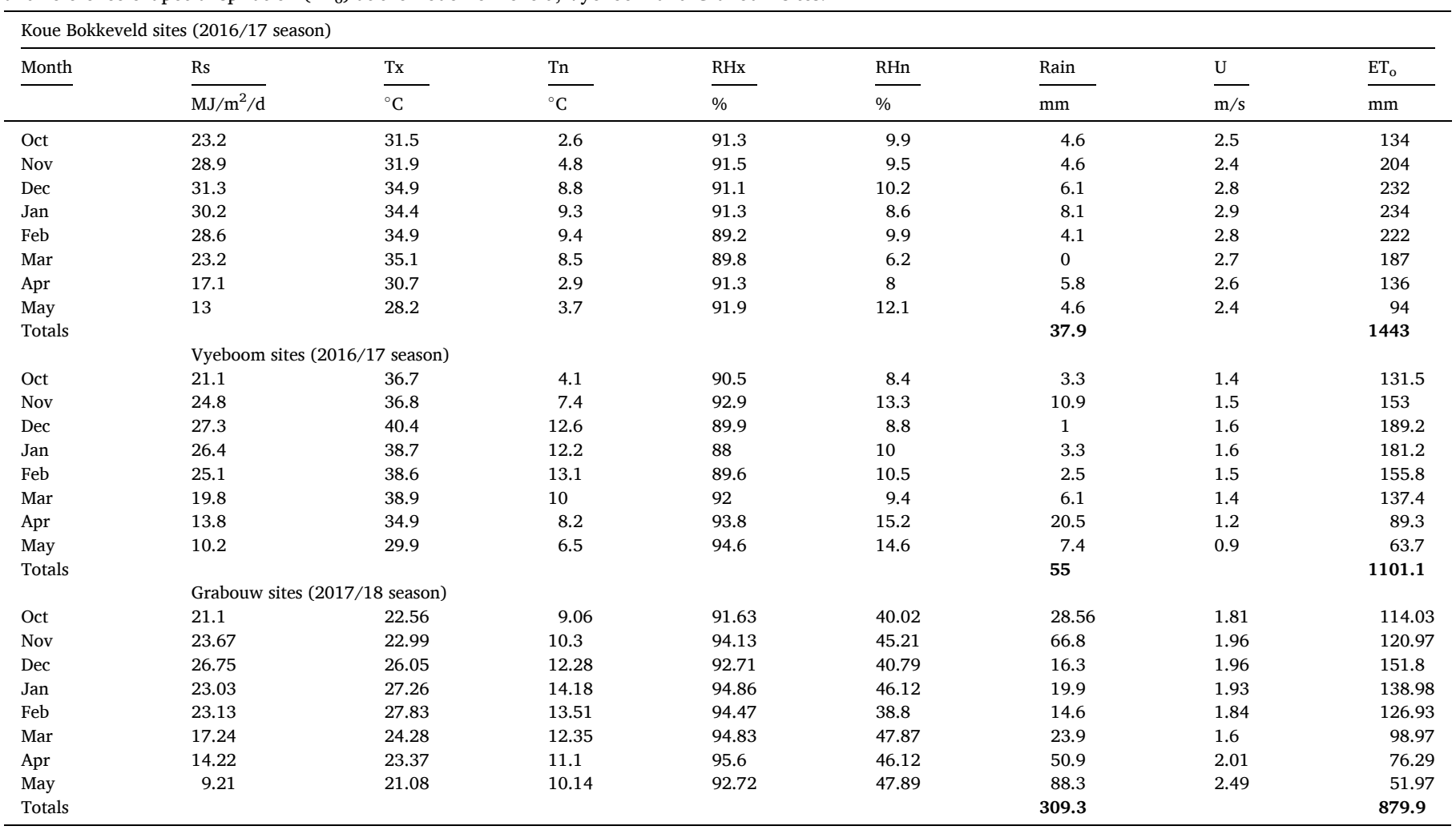

2016 to May 2017. Although most rain falls in winter from May to August, the amounts reported here were much lower than in normal years highlighting the impact of the drought. So irrigation was critical to compensate for the rainfall deficit. The seasonal total reference evapotranspiration $\left(\mathrm{ET}_{\mathrm{o}}\right)$, which is a measure of the atmospheric evaporative demand was about $1443 \mathrm{~mm}$ for $\mathrm{KBV}$ which was several orders of magnitude higher than the rainfall (Table 3), while it was $\sim 1101 \mathrm{~mm}$ in Vyeboom. The reference evapotranspiration was calculated using the modified Penman-Monteith equation for a short grass reference according to Allen et al. (1998). For Orchards 4 and 5 in Grabouw, the

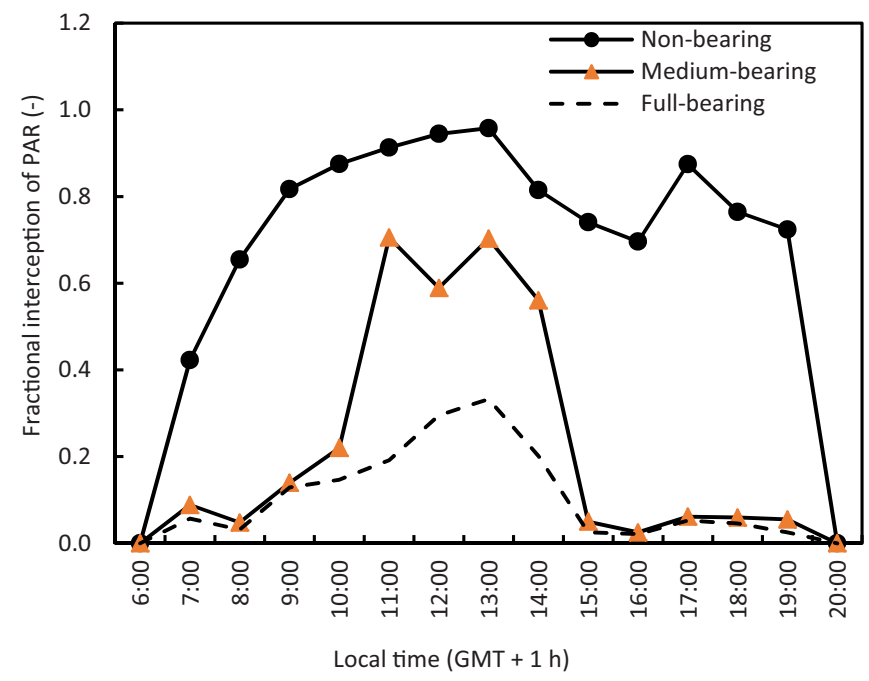

Fig. 2. The diurnal course of the fractional PAR reaching the orchard floors for a mature (Orchard 4), medium canopy cover (Orchard 3 ) and the young nonbearing orchard (Orchard 5). seasonal total rainfall during 2017/18 was much higher at about $309.3 \mathrm{~mm}$ while the reference evapotranspiration was slightly lower than at the other sites at about $879.9 \mathrm{~mm}$.

\subsection{Radiation interception and understorey leaf area index}

The radiation reaching the orchard floor is essential for driving processes such as transpiration and photosynthesis by the understorey vegetation. Examples of the fractional radiation interception are given in Fig. 2 in which three orchards age groups were considered. As expected, the understorey vegetation growing in the young orchard (Orchard 5) with the lowest tree fractional vegetation cover intercepted very high levels of PAR, up to $96 \%$ of the incident radiation at midday. In addition, interception levels remained high throughout the day as illustrated in Fig. 2. The influence of the high canopy cover was apparent for the medium bearing and the mature orchards. While the peak intercepted PAR at the orchard floor in the medium bearing orchards reached about $70 \%$, this only occurred for a short period when the sun was overhead between $11 \mathrm{~h} 00$ and $14 \mathrm{~h} 00$. Outside these times, on average less than $20 \%$ of the PAR reached the orchard floor (Fig. 2). The peak intercepted PAR by the mature orchard was much lower reaching about 33\% around midday. At low sun angles, the fractional PAR intercepted by this orchard was of the same order of magnitude as the bearing orchards. The low PAR reaching the orchard floor partly explained the rather sparse understorey vegetation compared, for example, to younger orchards.

Fig. 3 clearly shows the effect of management on the understorey leaf area index of the different orchards. Continuous $\mathrm{LAI}_{\mathrm{c}}$ data were obtained by linear interpolation between the monthly measurements and using information from the farm on the cutting dates. There was much more intense mowing of the understorey vegetation in the bearing and mature orchards with the peak $\mathrm{LAI}_{\mathrm{c}}$ hardly exceeding 0.15 . It is not clear why it was a priority to keep the grass short in mature and bearing orchards. 


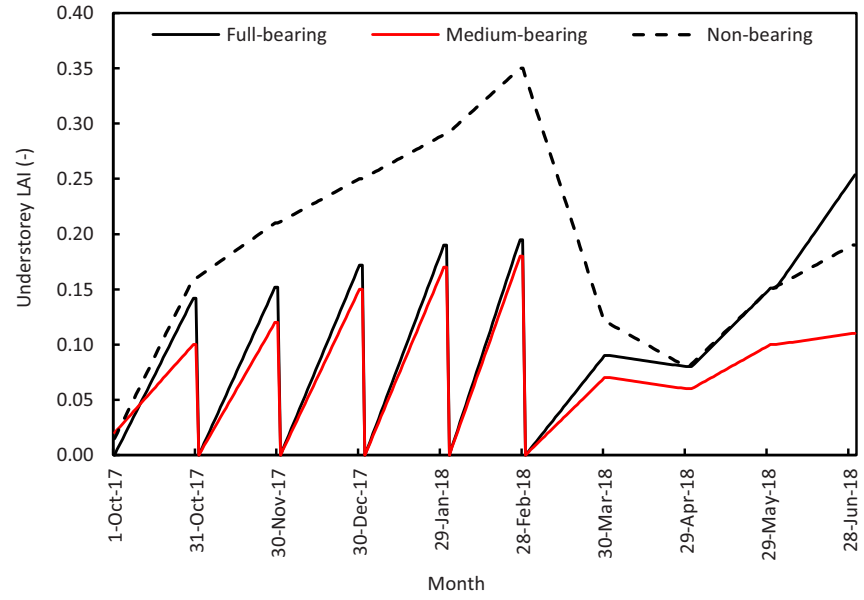

Fig. 3. The seasonal dynamics in the leaf area index of understorey vegetation for a mature (Orchard 4), medium canopy cover (Orchard 3) and the young non-bearing orchard (Orchard 5) in South Africa during the 2016 - 2017 growing season. These values are for the cover crop strips only, not expressed over the entire orchard floor.

Reducing competition for resources between the trees and the understorey vegetation and removing shelter for snakes which could be a hazard for the workers are probable factors. The understorey vegetation in the young orchard was only cut twice during the whole season, i.e. at the beginning and at the end of the season (Fig. 3). Consequently $\mathrm{LAI}_{\mathrm{c}}$ reached up to 0.35 in the middle of summer. After harvesting (February to March), the understorey vegetation was again allowed to flourish in all the orchards.

\subsection{Understorey vegetation water use dynamics and ET partitioning}

While the stem heat balance sap flow gauges have been used on grasses before (e.g. Ramírez et al., 2006; Senock and Ham, 1995), the sensors have not been used under natural conditions where thermal gradients are strong (Van Bavel and Van Bavel, 1990). For this reason, we calibrated these sensors under field conditions against the Infrared Gas Analyser (IRGA) and typical results are shown in Fig. 4. The micro sap flow sensor readings were of the same order of magnitude as the IRGA readings. However, there was a significant time shift between the sap flow and the IRGA readings suggesting significant capacitance effects due to the stored water (Dzikiti et al., 2007; Steppe et al., 2006). The area under the curve represents the daily total transpiration and this was similar between the two independent techniques. So, all understorey transpiration data were subsequently collected using the

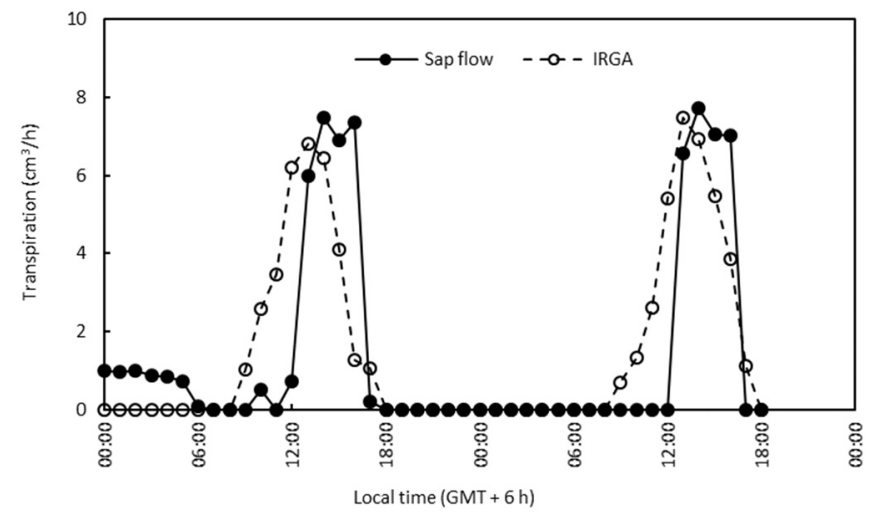

Fig. 4. Comparison of the transpiration measured from a single understorey plant using a micro stem heat balance sap flow sensor and the Infrared Gas Analyser over two clear days.

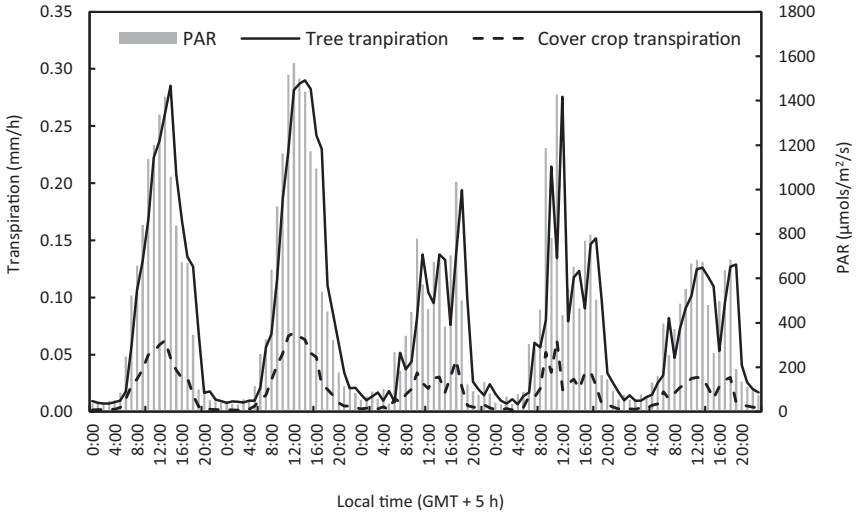

Fig. 5. Relationship between the incident PAR, measured tree transpiration in a medium bearing orchard (Orchard 1) and measured understorey transpiration over five days from 14 to 18 November 2016.

miniature sap flow sensors which are cheaper and the measurements could be automated.

An example of the time series of transpiration by the understorey vegetation and by the mature apple trees over a five day period as influenced by the incident PAR at the top of the tree canopies is shown in Fig. 5. There is a clear correlation between the tree transpiration and PAR flux while the understorey transpiration is also influenced by shading by the tree canopies. The contributions of the various orchard floor and tree fluxes to the whole orchard ET on typical clear days are shown in Fig. 6 when all the orchards were well-watered. In mature and medium bearing orchards, tree transpiration was the dominant flux while the orchard floor fluxes were the major contributors to ET in young orchards. The stem sap flow derived transpiration shown in Fig. 6a is shifted towards the afternoon because of tree capacitance effects and we did not correct for the time lags. In mature orchards, the approximate contribution of tree transpiration, understorey transpiration and soil evaporation to ET were approximately $65 \%, 25 \%$ and $10 \%$, respectively. The residuals due to lack of closure in the measured water balance components were applied equally to the understorey transpiration and the soil evaporation. These fluxes have the largest uncertainty due to the uneven wetting of the orchard floor and the variability in the understorey vegetation properties. In the medium bearing orchards, these contributions were $55 \%, 30 \%$ and $15 \%$, respectively. In young orchards the contributions were $(16 \%, 52 \%$ and $32 \%)$. There were no mulches in all the orchards studied.

The understorey water use data obtained during the campaigns indicated in Table 2 were used to validate the transpiration model and the results, pooled together from the various orchards, are shown in Fig. 7. The model predicted the understorey transpiration to within $12 \%$ of the measured values. To gain insights on how the understorey transpiration varied throughout the season, we applied the model to a mature (Orchard 4), medium bearing (Orchard 3), and young orchard (Orchard 5) using the $\mathrm{LAI}_{\mathrm{c}}$ data in Fig. 3 and the climate data. Typical results illustrating the effect of the varying tree canopy cover, represented by the orchard leaf area index (Fig. 8a) are shown in Fig. 8b. Water use by the understorey vegetation was similar at the beginning and end of the growing season when tree canopy cover was minimum. However, the rapid increase in tree canopy cover in mature orchards after spring flash resulted in a sharp decline in the understorey transpiration due to increased shading. A similar trend occurred with the medium bearing orchard, but there was an increase in the transpiration levels due to the rising atmospheric evaporative demand and shading that was not as pronounced as in the mature orchard. As expected, the modelled understorey transpiration was quite high in the young orchard with the peak daily water use just under $1.0 \mathrm{~mm} / \mathrm{d}$ on warm summer days (Fig. 8b). The variability in the modelled fluxes in Fig. 8b reflected the day-to-day variations in radiation reaching the orchard floor. The 

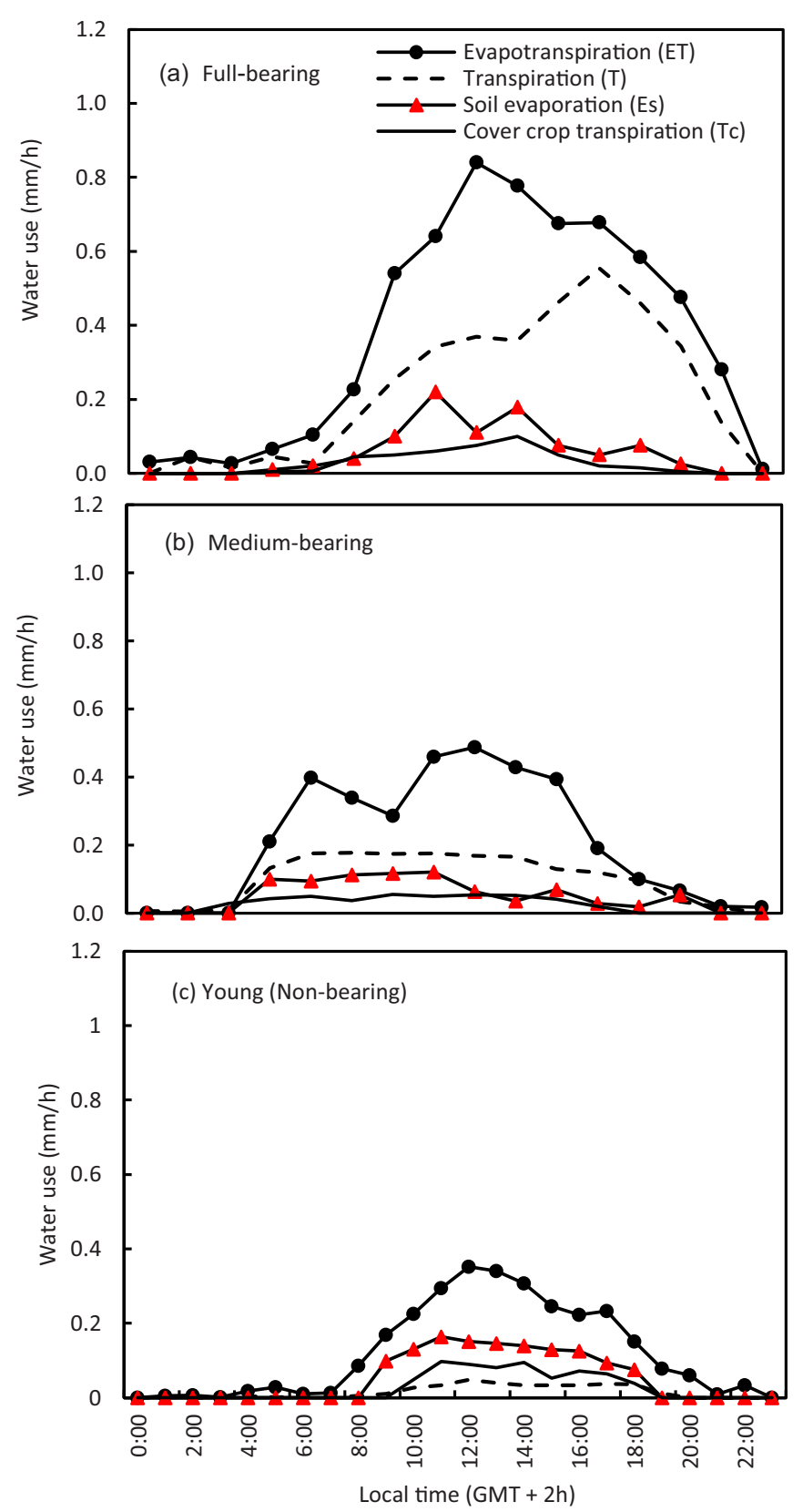

Fig. 6. Typical partitioning of evapotranspiration into its constituent components on clear days in micro-sprinkler irrigated orchards that are; (a) fullbearing (Orchard 4), (b) medium-bearing (Orchard 3), and; (c) young nonbearing (Orchard 5).

typical seasonal totals of the measured tree transpiration and the modelled understorey transpiration for the three orchard age groups are shown in Fig. 9. The seasonal total transpiration rates were about $640 \mathrm{~mm}$ for the mature orchard (Orchard 4), about $419 \mathrm{~mm}$ for the medium bearing (Orchard 3) and $198 \mathrm{~mm}$ for the young orchard (Orchard 5). The corresponding seasonal total for the understorey transpiration were $50 \mathrm{~mm}$ for the mature, $96 \mathrm{~mm}$ for the medium bearing and $153 \mathrm{~mm}$ for the young orchard. Seasonal total ET was not measured due to equipment limitations.

\section{Discussion}

The increasing frequency and severity of droughts due to climate change, and the growing competition for the limited water resources, are some of the key factors limiting economic growth, job creation, and

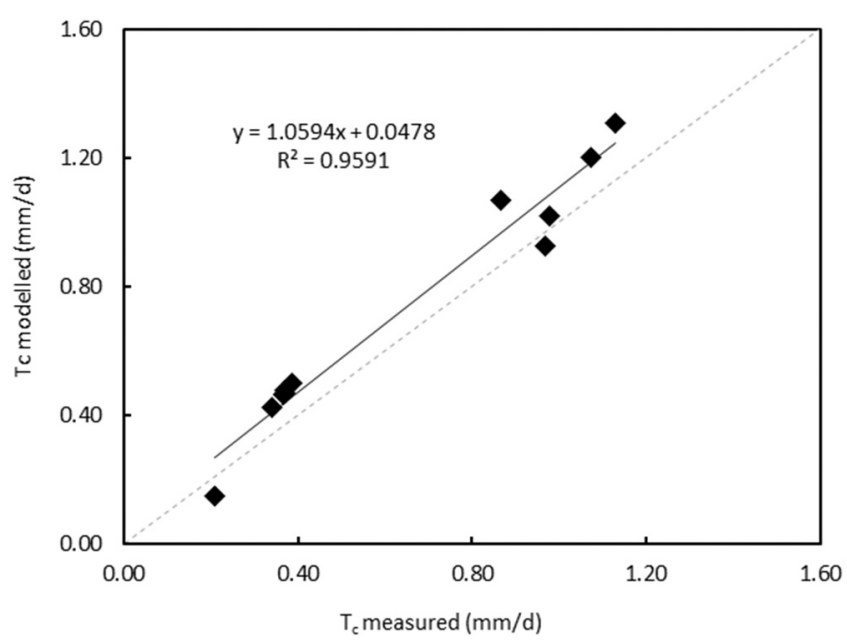

Fig. 7. Performance of the understorey transpiration model with data pooled from five orchards with different understorey vegetation characteristics.
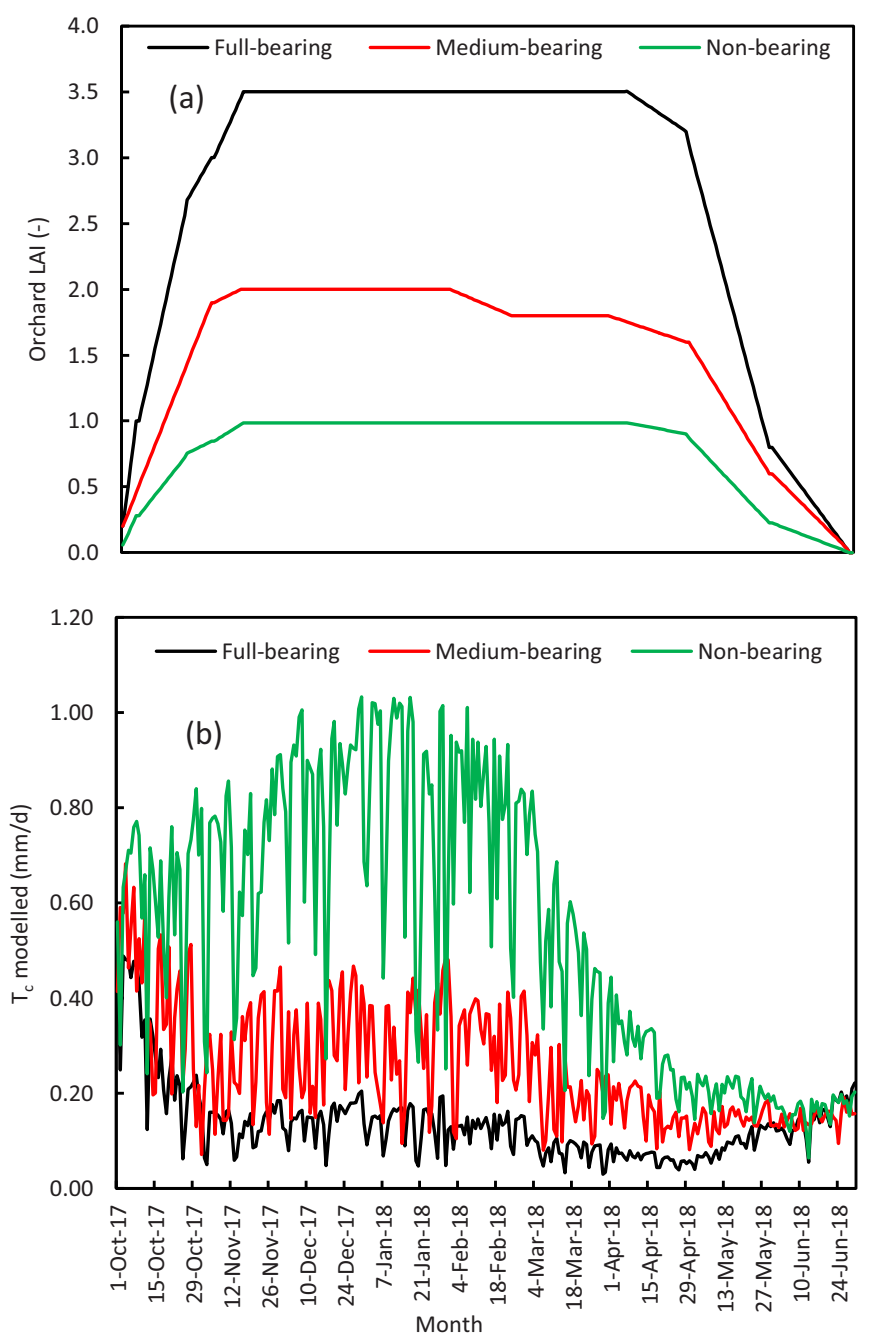

Fig. 8. Seasonal changes in (a) the leaf area index of three orchards of different age groups and (b) the modelled seasonal transpiration dynamics by the understorey vegetation. 

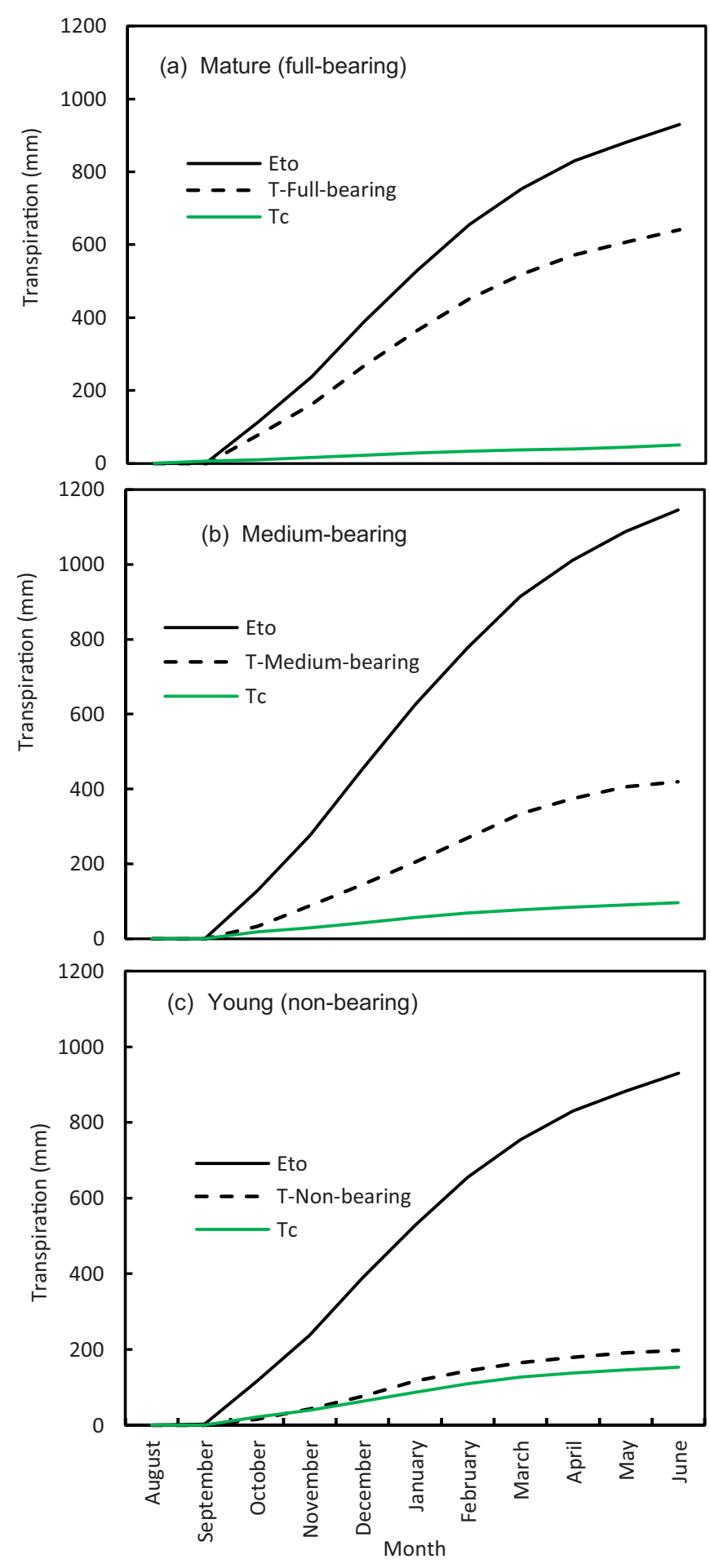

Fig. 9. Cumulative seasonal total $\mathrm{ET}_{\mathrm{o}}$, tree transpiration, and understorey transpiration for: (a) a full-bearing orchard (Orchard 4), (b) a medium-bearing orchard (Orchard 3), and (c) a young non-bearing orchard (Orchard 5).

food security in arid and semi-arid countries (Falkenmark, 2013; Reinders et al., 2013). In South Africa, for example, there is an increasing realization that irrigated agriculture is critical for the future prosperity of the country given the increasingly unreliable rainfall patterns (National development plan vision, 2030, Commission, N.P. 2013). Yet the available water resources are already fully allocated in more than $80 \%$ of the catchments across the country (Gush et al., 2019). For this reason, it is essential that major water users e.g. the fruit industry identify options to reduce water use in order to free up water to support further irrigation expansion (Reinders et al., 2013; Gush and Taylor, 2014).

In orchards, the transpiration component of the trees is usually associated with tree productivity while the orchard floor evaporative fluxes have, for a long time, been related to non-beneficial water losses (Kool et al., 2014; López-Olivari et al., 2016). Consequently, orchard floor management practices such as mulching and the use of localized irrigation systems e.g. drip irrigation are being widely used in orchards to reduce undesirable water losses (Hussain et al., 2018; Lötze and Kotze, 2014). In recent years however, two developments have influenced orchard floor management practices. The first relates to the need to reduce the use of agro-chemicals and pesticides in fruit production especially fruits that are destined for the export market. The second relates to the need to improve biodiversity in monoculture production systems such as orchards in order to enhance pests and disease management using eco-friendly practices (Jannoyer et al., 2011). Consequently, cover crops are increasingly part of the modern orchards and they have many pros and cons. One disadvantage of the cover crops relates to their unknown water requirements and there is a suspicion that some species use large quantities of water. Among the benefits from cover crops include; i) an ability to control pests and diseases by providing a habitat for beneficial insects, ii) improving the soil fertility e.g. through nitrogen fixation, iii) improving the soil structure, iv) suppressing the proliferation of weeds thereby limiting the use of herbicides. It is therefore not surprising that in many orchards in South Africa, the cover crops are actually watered to maintain a healthy orchard ecosystem. The choice of appropriate cover crops is therefore an important consideration for fruit farmers in the arid climates. In South Africa for example, there has been a raging debate for decades whether or not indigenous cover crop species use less water than exotic ones. However, no quantitative studies have been done to provide clarity on this subject.

In this study, we for the first time, provide insights on the typical water use rates by understorey vegetation measured under field conditions. A number of previous studies have indirectly estimated evaporative losses from the orchard floor as the difference between the whole orchard ET and transpiration measured using sap flow sensors or stable isotopes (Dzikiti et al., 2017; Er-raki et al., 2009; Gush and Taylor, 2014). The reliability of the orchard floor evaporative fluxes estimated in this way depends on the accuracy of both the ET and transpiration measurements. This study measured the transpiration using Granier probes in young orchards and the HRM in mature trees. The Granier probes are widely reported to significantly underestimate transpiration especially at high flow rates (Steppe et al., 2010; Dzikiti et al., 2011). In this study, we calibrated this method against weighing lysimeter data to minimize the errors. The HRM method, on the other hand, is designed to accurately measure low and reverse sap flows (Burgess et al., 2001). Its performance under high flow rates, characteristic of irrigated fruit tree crops such as apple trees, are not well known. However, the method has been calibrated against the weighing lysimeters on the high transpiring eucalyptus species and it gave reliable data as reported by Bleby et al. (2004). Given that we were unable to calibrate the HRM sensors on the apple trees, our tree transpiration data should therefore be interpreted within the constraints of this method.

Other studies that have quantified orchard floor evaporative fluxes have only measured the soil evaporation component and they assumed that the understorey vegetation transpiration was negligible (e.g. Dzikiti et al., 2018a; Gush and Taylor, 2014; Testi et al., 2006). The present study used miniature stem heat balance sap flow gauges to directly measure the water use of the mostly grass understorey vegetation. This method has been successfully used before on grasses by Senock and Ham (1995) and by Ramirez et al. (2006), but this has been under controlled environments in greenhouses or with potted plants. A major source of uncertainty with this method under natural uncontrolled conditions arises from the thermal gradients which can distort the signals, especially after sunrise (Steppe and Lemeur, 2004). The current study 
demonstrates that these gauges give transpiration readings that are comparable with the leaf level transpiration measurements recorded using the infrared gas analyser if adequate precautions are taken to minimize the soil-plant thermal gradients in grasses. In addition, the transpiration from the stem heat balance sap flow gauges closely matched that predicted by a simple version of the Priestley and Taylor model although we did not distinguish between the different understorey vegetation species as that would make the study very complex.

Besides directly quantifying the contribution of the understorey vegetation to the whole orchard ET, we also investigated how tree canopy cover influenced the understorey transpiration dynamics and we studied the seasonal dynamics of the understorey transpiration using the transpiration model. It is clear that tree canopy cover is a strong driver of the understorey transpiration in apple orchards and this is consistent with the observations by Herwitz et al. (2004) in a natural broadleaf forest. There are other factors that could have influenced the water use of the understorey vegetation e.g. the soil water content changes in the root zone. But we did not investigate these in this study. A sensitivity analysis of the model showed that increasing the leaf area index of the understorey vegetation $\left(\mathrm{LAI}_{\mathrm{c}}\right.$ ) by about $30 \%$ increased the understorey transpiration over the entire season by only $6 \%$ in mature compared to about $9 \%$ in young orchards. However, increasing the leaf area index of the orchard (LAI) by the same magnitude had a far greater impact on the understorey transpiration. The understorey transpiration decreased by about $40 \%$ and $22 \%$, respectively when the orchard LAI was increased by $30 \%$ in mature and young orchards. There was a smaller transpiration reduction in young orchards because of the low initial canopy size. This suggested that the influence of shading by the trees (high LAI) on the understorey transpiration was higher than that of an increase in the leaf area index of the understorey vegetation.

\section{Conclusion}

This study has shown that understorey vegetation contributes significantly to whole orchard water use, but this is strongly influenced by canopy cover of the trees. For example, the young orchard with a dense understorey used almost three times as much water as that in a mature orchard with a well maintained understorey vegetation. Again in young orchards with a dense understorey cover, transpiration by the understorey vegetation can account for close to $40 \%$ of the orchard ET. In mature orchards with large canopies, understorey transpiration did not have a significant contribution mainly due to shading by tree canopies. Therefore maximum water savings can be achieved by reducing the understorey vegetation cover when the trees are still young. It appears as if water savings due to a sparse understorey vegetation are less in mature orchards because the large canopies of the trees suppress the understorey transpiration rates.

\section{Declaration of Competing Interest}

The authors declare that they have no known competing financial interests or personal relationships that could have appeared to influence the work reported in this paper.

\section{Acknowledgements}

We would like to thank the Water Research Commission (WRC K5 2398/4) and the South African Apple and Pear Producers' Association (SAAPPA) for initiating this project and providing financial support. The South African Parliamentary Grant also funded this project through the Council for Scientific and Industrial Research (P1AHS01) and CSIR Young Researcher Establishment Fund (P4AHS00). We are grateful for their financial support. Funding from the National Research Foundation through the Thuthuka Instrumentation Fund (ECHS100) is also greatly acknowledged. We would also like to thank Mr Edward Lulane for helping with the IRGA measurements and all the farmers, farm managers and farm workers for providing study sites and assistance with fieldwork.

\section{References}

Agam, N., Kustas, W.P., Anderson, M.C., Norman, J.M., Colaizzi, P.D., Howell, T.A., Prueger, J.H., Meyers, T.P., Wilson, T.B., 2010. Application of the Priestley-Taylor approach in a two-source surface energy balance model. J. Hydrometeorol. 11, 185-198.

Allen, R.G., Pereira, L.S., Raes, D., Smith, M., 1998. Crop Evapotranspiration-Guidelines for Computing Crop Water Requirements-FAO Irrigation and Drainage Paper 56. Fao, Rome.

Anderson, R.G., Alfieri, J.G., Tirado-Corbalá, R., Gartung, J., McKee, L.G., Prueger, J.H., Wang, D., Ayars, J.E., Kustas, W.P., 2017. Assessing FAO-56 dual crop coefficients using eddy covariance flux partitioning. Agric. Water Manag. 179, 92-102.

Anderson, R.G., Zhang, X., Skaggs, T.H., 2018. Measurement and Partitioning of Evapotranspiration for Application to Vadose Zone Studies. https://doi.org/10.21 36/vzj2017.08.0155.

Bleby, T.M., Burgess, S.S.O., Adams, M.A., 2004. A validation, comparison and error analysis of two heat-pulse methods for measuring sap flow in Eucalyptus marginata saplings. Funct. Plant Biol. 31, 645-658.

Brutsaert, W., 1975. On a derivable formula for long-wave radiation from clear skies. Water Resour. Res. 11, 742-744.

Burgess, S.S.O., Adams, M.A., Turner, N.C., Beverly, C.R., Ong, C.K., Khan, A.A.H., Bleby, T.M., 2001. An improved heat pulse method to measure low and reverse rates of sap flow in woody plants. Tree Physiol. 21, 589-598.

Cammalleri, C., Agnese, C., Ciraolo, G., Minacapilli, M., Provenzano, G., Rallo, G., 2010. Actual evapotranspiration assessment by means of a coupled energy/hydrologic balance model: Validation over an olive grove by means of scintillometry and measurements of soil water contents. J. Hydrol. 392, 70-82.

Dzikiti, S., Volschenk, T., Midgley, S., Gush, M., Taylor, N., Lotze, E., Zirebwa, S. Ntshidi, Z., Mobe, N., Schmeisser, M., Doko, Q., 2018b. Quantifying Water Use and Water Productivity of High Performing Apple Orchards of Different Canopy Report to the, Water Research Commission.

Dzikiti, S., Steppe, K., Lemeur, R., Milford, J.R., 2007. Whole-tree level water balance and its implications on stomatal oscillations in orange trees [Citrus sinensis (L.) Osbeck] under natural climatic conditions. J. Exp. Bot. 58, 1893-1901.

Dzikiti, S., Verreynne, S.J., Stuckens, J., Strever, A., Verstraeten, W.W., Swennen, R., Theron, K.I., Coppin, P., 2011. Seasonal variation in canopy reflectance and its application to determine the water status and water use by citrus trees in the Western Cape, South Africa. Agric. . Meteorol. 151, 1035-1044.

Dzikiti, S., Gush, M.B., Volschenk, T., Taylor, N.J., Midgley, S.J.E., Lotze, E., Schmeisser, M., Doko, Q., 2017. Measurement and modelling of water use in high yielding apple orchards and orchards of different age groups in South Africa. Acta Hortic.

Dzikiti, S., Volschenk, T., Midgley, S.J.E., Lötze, E., Taylor, N.J., Gush, M.B., Ntshidi, Z., Zirebwa, S.F., Doko, Q., Schmeisser, M., Jarmain, C., Steyn, W.J., Pienaar, H.H., 2018a. Estimating the water requirements of high yielding and young apple orchards in the winter rainfall areas of South Africa using a dual source evapotranspiration model. Agric. Water Manag. 208. https://doi.org/10.1016/j.agwat.2018.06.017.

Er-raki, S., Chehbouni, A., Etudes, C.D., La, S. De, Ezzahar, J., Khabba, S., 2009. Evapotranspiration partitioning from sap flow and eddy covariance techniques for olive orchards in semi-arid region Evapotranspiration Partitioning from Sap Flow and Eddy Covariance Techniques for Olive Orchards in Semi-Arid Region. https:// doi.org/10.17660/ActaHortic.2009.846.21.

Falkenmark, M., 2013. Adapting to climate change: towards societal water security in dry-climate countries. Int. J. Water Resour. Dev. 29, 123-136.

Fernández, J.E., Diaz-Espejo, A., Hernandez-Santana, V., Cuevas, M. V., 2018. Does precision irrigation help to reduce water consumption in agriculture?, in: XXX International Horticultural Congress IHC2018: International Symposium on Water and Nutrient Relations and Management of 1253. pp. 199-206.

Gush, M., Taylor, N., 2014. The water use of selected fruit tree orchards (Volume 2): Technical report on measurements and modelling (WRC REPORT NO. 1770/2/14). Water Res. Comm. Pretoria, South Africa.

Gush, M., Dzikiti, S., Laan, M. Van Der, Steyn, M., Manamathela, S., Pienaar, H., 2019. Agricultural and Forest Meteorology Field quanti fi cation of the water footprint of an apple orchard, and extrapolation to watershed scale within a winter rainfall Mediterranean climate zone. Agric. Meteorol. 271, 135-147. https://doi.org/ 10.1016/j.agrformet.2019.02.042.

Herwitz, S.R., Johnson, L.F., Dunagan, S.E., Higgins, R.G., Sullivan, D.V., Zheng, J., Lobitz, B.M., Leung, J.G., Gallmeyer, B.A., Aoyagi, M., 2004. Imaging from an unmanned aerial vehicle: agricultural surveillance and decision support. Comput. Electron. Agric. 44, 49-61.

Hortgro, 2018. Key Deciduous Fruit Statistics-2018, South Africa. www.hortgro.co.za.

Hussain, S., Bashir, D., Sharma, M.K., Jamwal, M., 2018. Effect of orchard floor management practices on fruit production. Int. J. Curr. Microbiol. Appl. Sci. 7, 3627-3670.

Jannoyer, M.L., Le Bellec, F., Lavigne, C., Achard, R., Malézieux, E., 2011. Choosing cover crops to enhance ecological services in orchards: a multiple criteria and systemic approach applied to tropical areas. Procedia Environ. Sci. 9, 104-112.

Kool, D., Agam, N., Lazarovitch, N., Heitman, J.L., Sauer, T.J., Ben-gal, A., 2014. Agricultural and Forest Meteorology A review of approaches for evapotranspiration partitioning. Agric. Meteorol. 184, 56-70. https://doi.org/10.1016/j. agrformet.2013.09.003. 
Li, S.-G., Asanuma, J., Kotani, A., Davaa, G., Oyunbaatar, D., 2007. Evapotranspiration from a Mongolian steppe under grazing and its environmental constraints. J. Hydrol. 333, 133-143.

López-Bernal, Á., Alcántara, E., Testi, L., Villalobos, F.J., 2010. Spatial sap flow and xylem anatomical characteristics in olive trees under different irrigation regimes. Tree Physiol. 30, 1536-1544.

López-Olivari, R., Ortega-Farías, S., Poblete-Echeverría, C., 2016. Partitioning of net radiation and evapotranspiration over a superintensive drip - irrigated olive orchard. Irrig. Sci. 34, 17-31. https://doi.org/10.1007/s00271-015-0484-2.

Lötze, E., Kotze, W.P., 2014. The effect of organic and inorganic mulches on soil environment, root development and nutrient uptake of mature apple trees. Acta Hortic. 2014 (1018), 391-400.

Midgley, S.J.E., Lotze, E., 2011. Climate change in the Western Cape of South Africa: trends, projections and implications for chill unit accumulation. Acta Hortic. 1127-1134.

Mobe, N.T., Dzikiti, S., Zirebwa, S.F., Midgley, S.J.E., Loeper, W. Von, Mazvimavi, D., Ntshidi, Z., Jovanovic, N.Z., 2020. Estimating crop coe ffi cients for apple orchards with varying canopy cover using measured data from twelve orchards in the Western Cape Province, South Africa. Agric. Water Manag. 233, 106103 https://doi.org/ 10.1016/j.agwat.2020.106103.

Mupambi, G., Schmeisser, M., Dzikiti, S., Reynolds, S., Steyn, W.J., 2018. Ineffectiveness of foliar S-ABA application as an apple sunburn suppressant explained through effects on peel biochemistry and leaf ecophysiology. Sci. Hortic. 232, 256-263.

National development plan vision 2030, Commission, N.P., 2013. National development plan vision 2030 .

Ntshidi, Z., Dzikiti, S., Mazvimavi, D., 2018. Water use dynamics of young and mature apple trees planted in South African orchards: a case study of the Golden Delicious and Cripps' Pink cultivars, in: Proceedings of the International Association of Hydrological Sciences. https://doi.org/10.5194/piahs-378-79-2018.

Ortega-Farias, S., 2012. Evaluation of a Two-Layer Model and Sap Flow to Estimate Olive Transpiration Evaluation of a Two-Layer Model and Sap Flow to Estimate Olive Transpiration. https://doi.org/10.17660/ActaHortic.2012.951.17.

Ortega-Farías, S., Ortega-Salazar, S., Poblete, T., Kilic, A., Allen, R., PobleteEcheverría, C., Ahumada-Orellana, L., Zuñiga, M., Sepúlveda, D., 2016. Estimation of energy balance components over a drip-irrigated olive orchard using thermal and multispectral cameras placed on a helicopter-based unmanned aerial vehicle (UAV). Remote Sens. 8, 638.

Pienaar, L., Boonzaaier, J., 2018. DROUGHT POLICY BRIEF WESTERN CAPE AGRICULTURE. Western Cape Department of Agriculture (WCDoA) and the Bureau for Food and Agricultural Policy (BFAP), Elsenburg.

Ramírez, D.A., Valladares, F., Blasco, A., Bellot, J., 2006. Assessing transpiration in the tussock grass Stipa tenacissima L.: the crucial role of the interplay between morphology and physiology. Acta Oecol. 30, 386-398.
Reinders, F.B., van der Stoep, I., Backeberg, G.R., 2013. Improved efficiency of irrigation water use: a South African framework. Irrig. Drain. 62, 262-272.

Senock, R.S., Ham, J.M., 1995. Measurements of water use by prairie grasses with heat balance sap flow gauges. J. Range Manag. 48, 150-158.

Slatyer, R.O., Mcllroy, I.C., 1961. Practical microclimatology, with special reference to the water factor in soil-plant atmosphere relationships. Melbourne C.S.I.R.O.

Soil Classification Working Group, S.C.W, 1991. Soil classification: a taxonomic system for South Africa. Mem. Agric. Nat. Resour. South Afr. 15, 1-262.

Steppe, K., Lemeur, R., 2004. An experimental system for analysis of the dynamic sapflow characteristics in young trees: results of a beech tree. Funct. Plant Biol. 31, 83-92.

Steppe, K., Saveyn, A., Vermeulen, K., Lemeur, R., 2006. A comprehensive model for simulating stem diameter fluctuations and radial stem growth, in: III International Symposium on Models for Plant Growth, Environmental Control and Farm Management in Protected Cultivation 718. pp. 35-42.

Steppe, K., De Pauw, D.J.W., Doody, T.M., Teskey, R.O., 2010. A comparison of sap flux density using thermal dissipation, heat pulse velocity and heat field deformation methods. Agric. . Meteorol. 150, 1046-1056.

Swanson, R.H., Whitfield, D.W.A., 1981. A numerical analysis of heat pulse velocity theory and practice. J. Exp. Bot. 32, 221-239.

Testi, L., Villalobos, F.J., Orgaz, F., Fereres, E., 2006. Water requirements of olive orchards: i simulation of daily evapotranspiration for scenario analysis. Irrig. Sci. 24, 69-76.

Van Bavel, M.G., Van Bavel, C.H.M., 1990. Dynagage Installation and Operation Manual. Dynamax Inc., Houston, TX.

Villalobos, F.J., Testi, L., Orgaz, F., García-Tejera, O., Lopez-Bernal, A., GonzálezDugo, M.V., Ballester-Lurbe, C., Castel, J.R., Alarcón-Cabañero, J.J., NicolásNicolás, E., 2013. Modelling canopy conductance and transpiration of fruit trees in Mediterranean areas: a simplified approach. Agric. . Meteorol. 171, 93-103.

Volschenk, T., 2017. Evapotranspiration and crop coefficients of Golden Delicious/M793 apple trees in the Koue Bokkeveld. Agric. Water Manag 194, 184-191.

Wang, D., Wang, L., 2017. Dynamics of evapotranspiration partitioning for apple trees of different ages in a semiarid region of northwest China. Agric. Water Manag. 191, 1-15. https://doi.org/10.1016/j.agwat.2017.05.010.

Wullschleger, S.D., King, A.W., 2000. Radial variation in sap velocity as a function of stem diameter and sapwood thickness in yellow-poplar trees. Tree Physiol. 20, 511-518.

Zanotelli, D., Montagnani, L., Andreotti, C., Tagliavini, M., 2019. Evapotranspiration and crop coefficient patterns of an apple orchard in a sub-humid environment. Agric. Water Manag. 226, 105756. 